\title{
Poesía y oralidad
}

Mauricio Ostria GonZález

Universidad de Concepción

1. La obra literaria es construcción de un mundo imaginario, ficticio, por medio de palabras. En este sentido, la literatura posee un doble estatuto: por una parte, es un discurso verbal, sujeto a codificaciones lingüísticas, idiomáticas, retóricas; por otra, sin dejar de ser lenguaje, es artificio verosímil. Se sostiene sobre configuraciones lingüísticas, pero no es meramente lenguaje: lo trasciende para operar en un universo discursivo no pragmático sino imaginario, de significación profunda.

En tanto lenguaje, el texto literario significa, es decir, representa la realidad mediante un sistema codificado de signos y, consecuentemente, es un vehículo de conocimiento; pero también, por ser lenguaje, comunica, o sea, se constituye en medio de relación intersubjetiva, vehículo por el que los interlocutores dialogan y se expresan. Finalmente, su propia naturaleza lingüística convierte a la literatura en instancia de creación [Coseriu 1977; Ostria González 1989:23-39].

En tanto objeto artístico, ficticio, la literatura construye, con los signos del lenguaje, y por tanto también con sus funciones, un complejo imaginario que figura, por una parte, un mundo humano de significación relevante $y$, por otra, un acto de lenguaje, un discurso. El discurso real se desdobla internamente, mediante procesos de recursividad, en discurso(s) imaginario(s). La dimensión creadora del lenguaje encuentra, entonces, su significación más plena en la lengua poética, puesto que allí la palabra, sin dejar de ser palabra, se transforma en obra de arte. Muchos de los malentendidos acerca del fenómeno literario y de su estudio y enseñanza derivan de que, o se lo considera sólo como una forma específica del lenguaje, un tipo discursivo como cualquier otro o se lo proclama ente autónomo, imaginario, sin conexión alguna con el

*Esta ponencia fue leída en el XIV Congreso de la Sociedad Chilena de Lingüística (SOCHIL), U. de Los Lagos, Osorno (8-12 octubre de 2001) y forma parte del proyecto 1990464, financiado por Fondecyt. 
mundo ni con la actividad lingüística concreta. Por el contrario, yo estimo que lo específico de este fenómeno (la literatura) consiste en ser, simultáneamente, lenguaje (significación, comunicación, creación) y arte (constructo imaginario). En consecuencia, reitero, el carácter imaginario, figural, de la literatura no anula, en absoluto, sus posibilidades comunicativas o semánticas, o sea sus relaciones con la realidad; sólo que cambia su sentido. En otras palabras, aunque el discurso literario no opera en la realidad del mismo modo que el discurso pragmático, no deja por ello de ser lenguaje; lo que ocurre es que al imbricarse dialécticamente las funciones lingüísticas (semánticas y comunicativas) con las artísticas (objeto imaginario) dan origen a un proceso de ambiguación y autonomía significante, fundado en la liberación del discurso respecto de instancias exteriores inmediatas y a su condición de figura.

El texto literario supone, pues, la presencia de un tipo de acción verbal distinta, un mensaje de un cierto tipo y, al mismo tiempo, la transformación de las estructuras lingüísticas en objeto icónico, en universo imaginario. Este cosmos ficticio evocado por configuraciones de palabras no está constituido exclusivamente por los niveles, estratos o códigos pertenecientes a lo representado (personajes, circunstancias, aconteceres, vivencias), sino, además -y esto es capital para entender el fenómeno literario- por la situación comunicativa inmanente (factores y funciones constitutivos de un circuito comunicativo imaginario), que asume su rol de comunicación ficticia inscrita en el texto ${ }^{1}$.

2. Si bien, como señala Benveniste [1977], "el escritor se enuncia escribiendo y dentro de su escritura hace que se enuncien individuos", hay que añadir que, en el texto literario, tales enunciaciones internas asumen el carácter de ficticias y pueden, con frecuencia, más allá de que sus emisores y destinatarios no corresponden a instancias reales, no coincidir con el tipo, la forma o el soporte significante de la enunciación del escritor: una novela puede fingir ser un conjunto de cartas, un informe, una crónica; un poema, puede aparecer como cuento y hasta como un sermón. También los códigos son ficticios, por lo tanto un texto escrito en español puede fingir estarlo en árabe o en sánscrito.

Y lo que es más interesante para nuestros propósitos, un texto escrito puede imaginarse texto oral: ejemplos elocuentes en la literatura latinoamericana son el Martín Fierro, que además se propone como canto, y la mayor parte de los relatos rulfianos. Todavía más compleja es la situación de formas aparentemente orales cuya función es la de representar discursos no dichos como es el caso del estilo indirecto libre o de los diversos tipos de monólogo interior en

${ }^{1}$ Narrador, persona dramática, yo ensayista o hablante lírico y sus correlatos son construcciones ficticias y lingüísticas. 
los relatos y, claro, el discurso de la poesía. En este caso, la seudo oralidad se convierte en figura de interioridad, en imagen de silencio.

3. En el discurso de la poesía se da, pues, la paradoja de que para representar el silencio, la "música callada" (sentimientos y sensaciones como vivencias interiorizadas) se deba recurrir a una escritura que, a diferencia de lo que sucede con otros géneros o tipos discursivos, opera como pentagrama, es decir como soporte significante del significante sonoro. Debe advertirse, sin embargo, que la escritura poética, por ser precisamente escritura, no contiene en su materialidad los sonidos, entonaciones o ritmos concretos, propios de toda secuencia oral real, sino sólo las imágenes acústicas correspondientes a las unidades distintivas (fonemas, entonemas, esquemas rítmicos y cláusulas acentuales). Y entonces, esto dependerá, naturalmente, de los rasgos fonológicos propios del idioma en que se escriba el poema. Por ejemplo, sin salirnos del castellano, un lector español reconocerá, leerá y pronunciará fricativas interdentales opuestas a palatales, allí donde un latinoamericano neutralizará la oposición a favor del fonema fricativo palatal.

Entonces, la lectura en voz alta devolverá a la poesía su corporeidad sonora en plenitud, aunque, claro, cada lectura será necesariamente una interpretación singular del poema con sus énfasis y sus matices ${ }^{2}$. Así, Octavio Paz percibe que "el ritmo en el verso de César Vallejo procede del lenguaje peruano y está hecho de ensimismada soledad...". Y concluye: "El placer poético es placer verbal y está fundado en el idioma de una época, de una generación, de una comunidad" [1956: 276].

Desde un punto de vista más técnico, Olrich Belic enfatiza: "La estructura rítmica del verso depende del idioma. En el verso no hay nada que no sea dado por las propiedades y condiciones prosódicas de un idioma determinado" 3 [1972: 12]. En otras palabras, por ejemplo, en la poesía castellana no existe, no puede existir ningún verso con ritmo cuantitativa, porque el idioma carece de la oposición distintiva entre vocales largas y breves.

${ }^{2}$ Está claro que entender las funciones sonoras en poesía implica comprender la diferencia entre la fonética y la fonología, "vale decir, entre los sonidos como elenco de fenómenos físicos y el inventario de unidades funcionales, con capacidad diferenciadora, que se abstrae sobre la base de la realidad fonética” [Escobar 1970: 119].

${ }^{3}$ Sin embargo, esto no quiere decir que las condiciones rítmicas o prosódicas de un idioma determinen absolutamente la estructura del verso de modo absoluto. Baste recordar que el endecasílabo surgió en el italiano y el alejandrino en el francés. 
4. En un principio, la poesía (épica, lírica, dramática) fue oral ${ }^{4}$ : "unidades verbales rítmicas que aparecen y desaparecen, una tras otra, en un espacio invisible hecho de aire" [Paz 1990: 121]. Más tarde se apoyó en la escritura, sin abandonar del todo sus raíces orales 5 . La elección de las formas recortadas de los sistemas de versificación, la relevancia de los efectos sonoros en recitaciones, lecturas en voz alta, grabaciones, musicalizaciones, etc., ponen en evidencia los fuertes vínculos de la poesía con la dimensión oral del lenguaje. Desde entonces, desde la invención de la escritura, se manifestará en los textos poéticos una pugna entre la creciente ficcionalización de los efectos orales y la resistencia a la pérdida total de sonoridad. De hecho, la historia de la poesía manifiesta una especie de movimiento pendular entre tendencias que privilegian ora los efectos visuales ora los acústicos, sin faltar aquéllos de inestable equilibrio en que se procuró vincularlos en correlaciones y correspondencias ${ }^{6}$.

5. La persistencia de lo fónico en la poesía la preserva como fenómeno que, no obstante su soporte escritural, conserva su virtualidad sonora. "En todas las formas escritas de la poesía -señala Octavio Paz- el signo gráfico está siempre en función del oral", de modo que el lector de poesía "oye mentalmente, detrás del trazo las palabras del texto, su música verbal” [1990:122].

De aquí que los diversos recursos sonoros (eufonías, paronomasias, rimas, anáforas, medidas, acentos, ritmos, entonaciones, encabalgamientos, estructuras estróficas, etc.) no son en la verdadera poesía simples adornos o recursos retóricos sino elementos indispensables en la construcción de las visiones interiorizadas. Sonido y sentido se hacen inseparables y de ahí la imposibilidad de verdadera traducción de la poesía. "Todo concepto lingüístico aplicado a la poética -afirma Jabobson- coloca automáticamente en primer plano precisamente la idea de las relaciones recíprocas [entre la estructura fónica y el plano semántico]"

4“... la versificación era la base mnemónica y por ende autoritativa de la cultura oral..." [Rivers 1988: 15].

5"Los modernos, con la desaparición gradual de la poesía épica y de la tragedia versificada, hemos inventado el reducto de una poesía exclusivamente lírica” [Rivers 1988: 15].

${ }^{6} \mathrm{La}$ intuición de los poetas sobre las correspondencias parece corroborarse por los estudios lingüísticos y neurológicos: "La relación que una las oposiciones distintivas de la lengua y la sistemática de los colores, especialmente, abre perspectivas serias y prometedoras a un trabajo en común con físicos, antropólogos, psicólogos, historiadores del arte y lingüistas...

Las experiencias de los lingüistas sobre el simbolismo de los sonidos, sobre la asociación evidente e inequívoca entre las oposiciones de los sonidos del lenguaje y las oposiciones de sentido, tales como alto-bajo, claro-oscuro, agudo-romo, alegre-triste, etc., se caracterizan por resultados aún más positivos" [Jakobson 1980: 60-61]. 
[1980: 29]. En el mismo sentido, Octavio Paz señala: "En ningún otro género literario es de tal modo íntima la unión entre sonido y sentido como en la poesía. Esto es lo que distingue al poema de las otras formas literarias, su característica esencial. El poema es un organismo verbal rítmico, un objeto de palabras dichas y oídas, no escritas ni leídas" [1990: 122]. Y Rivers: "la mera versificación material impone al lector una semiosis totalmente diferente a la de la prosa” [1988:16]. Esto es especialmente cierto en poemas como los de Garcilaso o Fray Luis, de Juan de la Cruz o Luis de Góngora, entre los clásicos; de Rubén Darío, Federico García Lorca o Nicolás Guillén, entre los modernos.

6. La atmósfera de refinada delicadeza que crea Rubén Darío en el primer poema de Prosas profanas depende absolutamente de las resonancias sonoras de las palabras y los versos armónicamente combinados:

Era un aire suave, de pausados giros:

el hada Harmonía ritmaba sus vuelos, e iban frases vagas y tenues suspiros entre los sollozos de los violoncelos.

Sobre la terraza, junto a los ramajes, diríase un trémolo de liras eolias cuando acariciaban los sedosos trajes, sobre el tallo erguidas las blancas magnolias.

La orquesta perlaba sus mágicas notas; un coro de sones alados se oía; galantes pavanas fugaces gavotas cantaban los dulces violines de Hungría.

Es noche de fiesta, y el baile de trajes ostenta su gloria de triunfos mundanos. La divina Eulalia, vestida de encajes, Una flor destroza con sus blancas manos.

El teclado armónico de su risa fina A la alegre música de un pájaro iguala, Con los staccati de una bailarina Y las locas fugas de una colegiala.

¡Amoroso pájaro que trinos exhala bajo el ala a veces ocultando el pico; que desdenes rudos lanza abajo el ala, bajo el ala aleve del leve abanico! [Darío 1961: 615-16]. 
Hay textos líricos en que la dominancia de lo sonoro puede llegar a reducir hasta casi anular la dimensión semántica de las palabras. Es el caso del empleo de las llamadas jitanjáforas (puros juegos fónicos) en, por ejemplo, algunos poemas del cubano Nicolás Guillén:

\author{
¡Mayombe.bombe.mayombé! \\ Sensemayá la culebra... \\ ¡Mayombe.bombe.mayombé! \\ Sensematá no se mueve... \\ ¡Mayombe.bombe.mayombé! \\ Sensemayá la culebra... \\ ¡Mayombe.bombe.mayombé! \\ Sensemayá se murió. [Guillén 1957:]
}

7. Surgen evidentemente sugerencias melódicas y rítmicas que acercan la poesía a la música y a la danza. Por supuesto, no sólo el adjetivo lírico evoca la relación de la poesía y música. Los propios poetas se encargan de sugerirla a través de cantos, himnos, canciones y cantares, villancicos, coplas, romance, sonatinas, trovas, serenatas o seguidillas, preludios y salmos, rondas, etc. Recordemos, un poco al azar, algunos títulos de poemas que expresan una clara intención de evocación musical: "Sinfonía en gris mayor", "Nocturno", "Balada", "Canción desesperada", "Tango del viudo" o algunos libros: Cantos de vida y esperanza, El canto errante, El son entero, Motivos del son, Canto general, Barcarola, Canción de gesta, Cancionero sin nombre, Canciones rusas, La cueca larga, Semillas para un himno ${ }^{7}$.

8. El fortalecimiento de la vigencia y el prestigio de la escritura en el marco de nuestra cultura letrada ha provocado, no obstante, un creciente proceso de prosificación y hasta de prosaísmo en la poesía (el verso rimado y medido ha cedido su lugar, primero, al verso blanco o suelto, luego al verso libre y, por fin, a secuencias o tiradas que buscan, por sobre todo, resaltar las posibilidades visuales de tipografías y otros efectos gráficos, así como las espaciales de la distribución en la página. Esta idea de la poesía como escritura es expresada lúcidamente por Enrique Lihn: "No quiero fingir que hablo cuando escribo. $\mathrm{Ni}$ menos aún que canto o toco un piano de palabras. Ni conversación de extramuros o de salón ni organillos ni música de cámara. La palabra escritura hay que tomarla al pie de la letra" [Lihn 1997: 387].

${ }^{7}$ Henríquez Ureña pensaba en el origen común de ciertos vocablos referidos al verso, a la música y a la danza en el Caribe [cf. Matos Moquete 1989: 554]. 
9. Paradojalmente, mientras más parece acentuarse el dominio de la letra y la escritura en la moderna práctica de la poesía y de la literatura, en general, la que adopta predominantemente el carácter de texto escrito -incluso los textos tradicionales, populares o folclóricos suelen llegar al público transcritos o impresos-, más parece acentuarse en ella la nostalgia de la palabra oral. Tendencia, esta última, apoyada fuertemente en la presión de los medios audiovisuales pragmáticos y artísticos ${ }^{8}$.

10. Uno de los casos más representativos del conflicto y la interferencia entre oralidad y escritura es, no hay duda, el de la poesía de Nicanor Parra. Al respecto, Ivette Malverde ha escrito palabras certeras y esclarecedoras: "la interacción entre oralidad y escritura tiene que ver [...] con los rasgos generales de la producción parriana y con el proyecto del autor de que sus libros son 'simultáneamente un documento literario y a la vez un documento visual', ya que el arte moderno, como dice él, es el de imágenes visuales, y el arte contemporáneo por 'antonomasia es la televisión'” [Malverde 1985-1986: 79]?.

Malverde caracteriza del siguiente modo el circuito comunicativo imaginario de los Sermones: "La situación discursiva de este texto es propuesta como la de un espectáculo popular festivo, que requiere, por lo tanto, un lenguaje oral, coloquial $^{10}$. El hablante del poema introductor origina un discurso que figura emitirse oralmente pero que es escrito, lo que le permite valerse tanto de procedimientos propios de la oralidad como de la escritura. Al hacer uso de estas dos posibilidades amplía las opciones del discurso, produciéndose un fenómeno de travestismo verbal en el que la escritura se inviste de oralidad y en el que

${ }^{8}$ El carácter esencialmente fónico del poema ilumina, según Octavio Paz, el "verdadero significado de la lectura en público de poemas [...]. Es un regreso al origen de la poesía, un volver a la fuente. Y por esto mismo las posibilidades de la pantalla de televisión son inmensas. En primer término, la creciente popularidad de los casetes nos libera de la tiranía del 'rating' y abre el camino a la pluralidad de públicos. En seguida: en la pantalla de televisión confluyen las dos grandes tradiciones poéticas, la escrita y la hablada. La pantalla es una página favorable, incluso por sus dimensiones, al diseño de composiciones no menos sino más complejas que la ideada por Mallarmé. Además, las letras aparecen en distintos colores y, diferencia substancial, en movimiento. Por otra parte, la página se transforma en una superficie animada, que respira, transcurre y cambia de un color a otro. Al mismo tiempo, la voz humana, mejor dicho las voces, pueden enlazarse y combinarse con las letras. Por último: las imágenes visuales y los elementos sonoros, en lugar de ser meros adornos, pueden transformarse en partes orgánicas del cuerpo mismo del poema” [1990: 122-123].

${ }^{9}$ Cf. Morales 1972: 219.

${ }^{10}$ En los poemas I y LXIII -señala Malverde- Parra explicita la aparente oralidad de su discurso [1985-1986: 84]. 
la oralidad se escribe [...] los procedimientos del lenguaje oral serán reproducidos a través de la escritura [1985-1986: 79].

11. También Enrique Lihn, en su afán de expandir los dominios de la poesía, incluye el discurso oral tomado directamente 'del natural' para estructurar el discurso polifónico de su poemario Estación de los desamparados: "En los poemas comparto el pronombre -suerte de contrapunto- con amigos y conocidos limeños, cuyos nombres eludî", de modo que su libro viene a ser "una crónica del Perú: repetición, más o menos literal, de textos orales harto inocentes por lo demás como se verá; obra de montaje con materiales del natural" [1997: 398].

12. No obstante la fuerte presión de la letra, el verso y sus resonancias fónicas debiera continuar manifestando su presencia en la poesía, no sólo como elemento ornamental o mnemotécnico, sino según agudamente lo advierte Jakobson, porque el verso, como lo sugiere su propia etimología, "contiene la idea de un retorno regular" [1990: 80]. Aun el verso libre en su juego de regularidades y quiebres permite romper la linealidad del tiempo e insertarnos en el tiempo cíclico del verbo como "consagración del instante" donde la escritura pacta y se funde con la otredad sonora, el yo con el tú, el sujeto de enunciación con el sujeto de enunciado en un juego de resonancias y ecos, repercusiones y sugerencias sólo posibles en el serio juego de la poesía.

\section{REFERENCIAS}

Belic, Olrich. 1972. El español como material del verso, Valparaíso, Ediciones Universitarias.

Benveniste, Emile. 1977. Problemas de lingüistica general II, México, D.F., Siglo XXI. Coseriu, Eugenio. 1977. El hombre y su lenguaje, Madrid, Gredos.

Darío, Rubén. 1851. Poesías completas, Madrid, Aguilar, 9a ed.

Escobar, Alberto. 1970. La partida inconclusa. Teoría y método de interpretación literaria, Santiago, Universitaria.

Guillén, Nicolás. 1957. Songoro cosongo, Buenos Aires, Losada.

Jakobson, Roman. 1980. Lingüística, poética, tiempo. Conversaciones con Krystina Pomorska, Barcelona, Crítica.

Lihn, Enrique. 1997. El circo en llamas. Una crítica de la vida, Santiago, Lom (ed. de G. Marín).

Malverde Disselkoen, N. Ivette. 1985-1986. "La interacción escritura-oralidad en el discurso carnavalesco de los Sermones y prédicas del Cristo de Elqui", Acta Literaria, 10-11: 77-89. 
Matos Moquete, Manuel. 1986. "Investigación lingüístico-literaria en Pedro Henríquez Ureña. La versificación”, Actas del VII Congreso de ALFAL, Santo Domingo, ALFAL.

Morales Toro, Leonidas. 1972. La poesía de Nicanor Parra, Santiago, U. Austral/Ed. Andrés Bello.

Ostria González, Mauricio. 1989. Escritos de varia lección. Ocho estudios, Concepción, Sur.

Paz, Octavio. 1990. La otra voz. Poesía y fin de siglo, Buenos Aires, Seix Barral.

Rivers, Elías L. 1988. "La oralidad y el discurso poético", Edad de Oro 37: 15-20.

A paradoxical situation occurs in poetic discourse: to represent silence, "silent music" (internal feelings and sensations), it is necessariy to have recourse to a writing that, unlike other kinds of discourse, acts as a musical notation, as a material support of the "significant". Thus poetic writing, precisely due to its nature of writing, does not contain real sounds, melodies or rithms, which are part of actual oral sequence, but only the acoustic images that corresponde to distinctive segments.

The persistence of phonetic dimension maintains poetry as an occurrence that, in spite of the scriptural support, conserves its audible virtuality, so that the reader "hears in his mind, behind the written words shape, the words of the text, its verbal music" (O. Paz). 